\title{
Correction to: Automated diagnosis system for detection of the pathological brain using fast version of simplified pulse-coupled neural network and twin support vector machine
}

\author{
Ravi Shanker ${ }^{1} \cdot$ Mahua Bhattacharya ${ }^{1}$ \\ Published online: 27 July 2021 \\ (C) Springer Science+Business Media, LLC, part of Springer Nature 2021
}

\section{Correction to: Multimedia Tools and Applications (2021) https://doi.org/10.1007/s11042-021-10937-6}

In the original publication of this article, all equations contain added data "aligned" and eqs. 16 and 18 are incomplete. The references were also not in alphabetical order. The original article has been corrected.

Publisher's note Springer Nature remains neutral with regard to jurisdictional claims in published maps and institutional affiliations.

The online version of the original article can be found at https://doi.org/10.1007/s11042-021-10937-6

\section{Ravi Shanker}

ravis@iiitm.ac.in; rsmiet60@gmail.com

Mahua Bhattacharya

mb@iiitm.ac.in

1 ABV-Indian Institute of Information Technology and Management, Morena Link Road, Gwalior 474015, India 